\title{
Efficacy and Safety of USG-guided 95\% Ethanol Sclerotherapy in Solitary Benign Thyroid Cysts
}

\author{
Rajeev K Nishad ${ }^{1}$, Anil K Jain ${ }^{2}$, Ashwani Kumar ${ }^{3}$, Rajesh Kumar ${ }^{4}$, Mangal Singh ${ }^{5}$
}

\begin{abstract}
Thyroid nodule is frequently encountered thyroid diseases and is characterized by growth of abnormal tissues into the thyroid gland. Solitary nodule, defined as palpable, clinically detectable single nodule in otherwise normal thyroid gland, usually presents as asymptomatic mass that is discovered either by patient or clinician.

Materials and methods: Twenty patients meeting inclusion criteria were included in study. Under strict aseptic conditions, using ultrasonographic guidance, fluid from cyst was aspirated and $95 \%$ ethanol was slowly (approximately $1 \mathrm{~mL} /$ minute) instilled into cavity to a volume of approximately $50 \%$ of volume of aspirated fluid. Patients were called for follow-up at an interval of 1 month for 3 months. Ultrasound was done to document volume of cyst, intracystic fibrosis and vascularity.

Results: The mean pre-procedure volume of cysts was $3.605 \mathrm{~cm}^{3}$. After instillation of ethanol, the mean volumes at the end of $1 \mathrm{st}$, 2nd and $3 \mathrm{rd}$ month of treatment were respectively $1.665 \mathrm{~cm}^{3}, 0.9585 \mathrm{~cm}^{3}$ and $0.442 \mathrm{~cm}^{3}$. The mean volume reduction rates were calculated. Smaller cysts demonstrate better results than the larger cysts i.e., cyst size in range of $2.1-2.5 \mathrm{~cm}^{3}$ shows $97.14 \%$ reduction after 3 months, while cysts of $>4.1 \mathrm{~cm}^{3}$ had mean reduction of $71.79 \%$ only.

Conclusion: In the management of benign euthyroid cysts, USG-guided percutaneous ethanol injection is a cost-effective and efficient nonsurgical treatment modality with higher success rates. It is a relatively safe procedure with very low or no complication rates and has better patient compliance.

Clinical significance: A non-surgical and cost-effective procedure can be treatment of choice for appropriately selected patient thus beneficial to greater majority of society.

Keywords: Ethanol, Sclerotherapy, Solitary thyroid nodule, Thyroid cyst.

International Journal of Phonosurgery \& Laryngology (2020): 10.5005/jp-journals-10023-1181
\end{abstract}

\section{INTRODUCTION}

A solitary nodule is defined as a palpable single clinically detected nodule in the thyroid gland that is otherwise normal. Its incidence varies among populations and geographic regions. Epidemiologic studies have shown the prevalence of palpable thyroid nodules to be approximately $5 \%$ in women and $1 \%$ in men living in iodine deficient parts of the world.

The thyroid nodule can be solid or cystic in nature. About 15 to $30 \%$ of thyroid nodules are cystic in nature..$^{1-5}$ Chances of the malignancies are more in solid and hypoechoic nodules. However cystic nature does not rule out malignancy. ${ }^{3,5}$

Simple aspiration of benign cystic thyroid nodules results in high rates of recurrence. ${ }^{6,7}$ Although surgery is curative for benign cystic thyroid nodules, there is a risk of complications.

Patients usually seek treatment of benign cystic thyroid nodule for cosmetic reason or due to compressive effect of large nodule resulting in dysphagia. ${ }^{8}$ Radioactive iodine ablation is effective but requires special equipment and is expensive. Tetracycline instillation has not been proven effective in reducing the size of thyroid cysts. ${ }^{9}$

Another nonsurgical therapeutic option in cystic thyroid nodule is sclerotherapy using percutaneous ethanol injection (PEI). ${ }^{10,11}$ The aim of our study was to evaluate the effectiveness and safety of ultrasound (USG)-guided PEl in cystic thyroid nodules.

\section{Materials and Methods}

\section{Study Design}

Our study is hospital-based prospective study of 1-year duration.

\footnotetext{
${ }^{1-2}$ Department of ENT and HNS, Chirayu Medical College, Bhopal, Madhya Pradesh, India

${ }^{3}$ Department of ENT, Pushpanjali Hospital and Research Centre, Agra, Uttar Pradesh, India

${ }^{4}$ Department of ENT, District Hospital, Jaunpur, Uttar Pradesh, India

${ }^{5}$ Department of ENT, MLN Medical College, Prayagraj, Uttar Pradesh, India
}

Corresponding Author: Anil K Jain, Department of ENT and HNS, Chirayu Medical College, Bhopal, Madhya Pradesh, India, Phone: +91 8866150454, e-mail: jaindranil@gmail.com

How to cite this article: Nishad RK, Jain AK, Kumar A, et al. Efficacy and Safety of USG-guided 95\% Ethanol Sclerotherapy in Solitary Benign Thyroid Cysts. Int J Phonosurg Laryngol 2020;10(1):9-12.

Source of support: Nil

Conflict of interest: None

\section{Methods}

After approval of the Institutional Ethics Committee, the study was conducted over a period of 1 year from April 2013 to April 2014 on selected patients with solitary cystic thyroid swelling, visiting Otorhinolaryngology and Head and Neck surgery outpatient department in a tertiary-care center. All patients with a clinical suspicion of a thyroid nodule were subjected to USG of the neck. In patients having predominantly cystic nodules (i.e., $>2 / 3$ of the swelling having cystic component), fine-needle aspiration cytology was performed under strict aseptic conditions. A thyroid profile was obtained in each of them. A total of 20 patients were

(-) The Author(s). 2020 Open Access This article is distributed under the terms of the Creative Commons Attribution 4.0 International License (https://creativecommons. org/licenses/by-nc/4.0/), which permits unrestricted use, distribution, and non-commercial reproduction in any medium, provided you give appropriate credit to the original author(s) and the source, provide a link to the Creative Commons license, and indicate if changes were made. The Creative Commons Public Domain Dedication waiver (http://creativecommons.org/publicdomain/zero/1.0/) applies to the data made available in this article, unless otherwise stated. 
diagnosed to have non-neoplastic, solitary, euthyroid cyst and were included in the study. Patients included in the study were those having single clinically palpable thyroid nodule, predominantly cystic, with cosmetic or pressure symptoms, above 10 years of age, with no previous history of sclerosant therapy, neck surgery, neck irradiation, or any cardiovascular disease. Bedridden patients, nursing mothers, pregnant women, or patients having malignant thyroid swelling were excluded. Also excluded were patients having septate cysts. It is noteworthy to mention that the size of the cyst was not a selection criterion in this study.

Under strict aseptic condition, using ultrasonographic guidance, fluid from the cyst was aspirated, and 95\% ethanol was slowly (approximately $1 \mathrm{~mL} /$ minute) instilled into the cavity to a volume of approximately $50 \%$ of the volume of aspirated fluid. The injection of ethanol was stopped if ethanol leaked out of the nodule or the patient complained of pain. The needle or catheter was withdrawn, gentle pressure was applied over the puncture site for 10-15 minutes, and the patient was observed for any signs of complications. The patients were discharged same day and called for follow-up at an interval of 1 month for 3 months. At each follow-up visit, the patients were evaluated for any side effects such as scarring and obvious reduction or increment in size of cysts. An ultrasound was done to document volume of the cyst, intracystic fibrosis, and vascularity.

According to the working hypothesis, more than $50 \%$ reduction from the baseline volume was accepted as procedural success.

The effect of the therapy was presented as the volume reduction rate (volume reduction rate $(\%)=$ [initial volume - final volume after treatment]/initial volume $\times 100$ ), and each case was classified into one of the following six groups: cysts with a $<50 \%$, $50-60 \%, 60-70 \%, 70-80 \%, 80-90 \%$, and $>90 \%$ reduction in volume of cyst.

95\% ethanol was reinstilled (after 3 months of follow-up) if there was no significant reduction in the cyst volume (i.e., reduction by $<50 \%$ of the initial volume). Such patients were subsequently called after 1 month to ascertain the results. If even after 3 months of reinstillation significant improvement could not be obtained, then patient was advised for surgery.

The volume reduction rate at each month of follow-up is compared to the pretreatment volume using paired $t$ test and the statistical software used to calculate $p$ value was SPSS software.

\section{Results}

The mean age of the patients included in the study was 36.65 years and ranged between 18 years and 51 years. In all, $90 \%(n=18)$ of the patients were females and $10 \%(n=2)$ were males. Majority $(75 \%)$ of the patients had their cyst in right lobe of thyroid and $25 \%$ in left. No cyst was found in isthmus. In all, $25 \%$ presented within 2 months, $55 \%$ of patients presented within 2-4 months of onset of symptoms, and the remaining $20 \%$ within 4 to 6 months. Most (40\%) of the patients had their initial cyst volume in the range of $3.6-4.0 \mathrm{~cm}^{3}$. In all, $35 \%$ patients had volume of $3.1-3.5 \mathrm{~cm}^{3}, 15 \%$ had a volume of $4.1-4.5 \mathrm{~cm}^{3}$, while $5 \%$ patients had their cyst volume in $2.1-2.5 \mathrm{~cm}^{3}$ and $2.6-3.0 \mathrm{~cm}^{3}$ each. The mean preprocedure volume of cysts was $3.605 \mathrm{~cm}^{3}$. After instillation of ethanol, the mean volume at the end of first, second, and third month of treatment were, respectively, $1.665 \mathrm{~cm}^{3}, 0.9585 \mathrm{~cm}^{3}$, and $0.442 \mathrm{~cm}^{3}$. The mean volume reduction rates were calculated to be $53.81 \%, 73.97 \%$, and $87.73 \%$ at the end of first, second, and third month of treatment, respectively.
Smaller cysts had better results than the larger cysts, i.e. cyst size in range of 2.1 to $2.5 \mathrm{~cm}^{3}$ had $97.14 \%$ reduction after 3 months, while cysts of $>4.1 \mathrm{~cm}^{3}$ had mean reduction of $71.79 \%$ only (Fig. 1).

The reduction in volume of cysts at first follow-up visit after PEl was found to be statistically significant ( $p$ value $<0.05$ ). Further reduction continued even in subsequent visits, and the resulting volume was significantly less than the previous volumes (Table 1).

Second instillation of sclerosing agent (95\% ethanol) was considered in only two patients who did not show significant reduction ( $>50 \%$ of initial volume) in their cyst size even after 3 subsequent months of follow-up after instillation of sclerosing agent. After second installation, one of them showed a volume reduction rate of $98.7 \%$ and the other showed that of $88.9 \%$, with the mean being $92.39 \%$ (Table 2).

In the present study, only $20 \%(n=4)$ of patients complained of transient burning pain at the time of instillation of ethanol in the cyst that was managed conservatively.

\section{Discussion}

Benign cystic thyroid nodules are a commonly encountered entity in day-to-day otolaryngology practice worldwide. In case of benign cystic thyroid nodule, the main reason for seeking medical attention is usually cosmetic or due to compressive effect of large nodule resulting in dysphagia. ${ }^{8}$ Minimally invasive procedure such as simple aspiration of cyst results in high recurrence rate. ${ }^{6,7}$ Surgery has advantage of complete cure but is not free of complications.

Tetracycline injections are not effective, and radioactive iodine is costly and requires special instruments. ${ }^{9}$

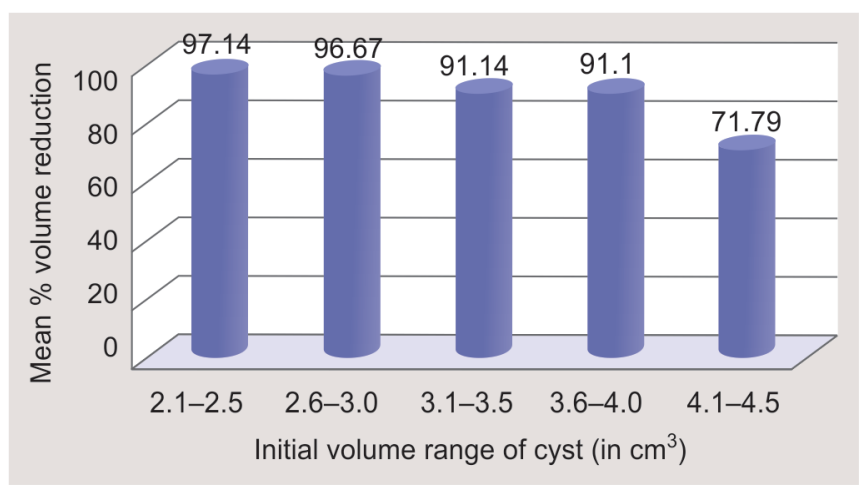

Fig. 1: Correlation of initial cyst volume and percentage reduction after third month of PEI

Table 1: Comparison of reduction in size of cyst

\begin{tabular}{|c|c|c|}
\hline S. no. & Comparison of reduction in size & Statistical significance \\
\hline 1 & $\begin{array}{l}\text { Pre-procedure size }\left(3.605 \mathrm{~cm}^{3}\right)-1 \mathrm{st} \\
\text { month follow-up size }\left(1.665 \mathrm{~cm}^{3}\right) .\end{array}$ & $p<0.05$ \\
\hline 2 & $\begin{array}{l}\text { 1st month follow-up size } \\
\left(1.665 \mathrm{~cm}^{3}\right)-2 \mathrm{nd} \text { month follow-up } \\
\text { size }\left(0.9385 \mathrm{~cm}^{3}\right)\end{array}$ & $p<0.05$ \\
\hline 3 & $\begin{array}{l}\text { 2nd month follow-up size } \\
\left(0.9385 \mathrm{~cm}^{3}\right)-3 \text { rd month follow-up } \\
\text { size }\left(0.442 \mathrm{~cm}^{3}\right) \text {. }\end{array}$ & $p<0.05$ \\
\hline 4 & $\begin{array}{l}\text { Pre-procedure size }\left(3.605 \mathrm{~cm}^{3}\right)-3 \mathrm{rd} \\
\text { month follow-up size }\left(0.442 \mathrm{~cm}^{3}\right)\end{array}$ & $p<0.05$ \\
\hline
\end{tabular}


USG-guided 95\% Ethanol Sclerotherapy in Solitary Benign Thyroid Cysts

Table 2: Volume reduction after 3 months of second installation of sclerosant in two patients

\begin{tabular}{lllll}
\hline S.no. & $\begin{array}{l}\text { Volume at 1st instillation (taken } \\
\text { as initial volume) }\end{array}$ & $\begin{array}{l}\text { Volume after 3 months of 1st } \\
\text { installation of sclerosing agent }\end{array}$ & $\begin{array}{l}\text { Volume after 3 months of 2nd } \\
\text { installation of sclerosing agent }\end{array}$ & $\begin{array}{l}\text { Volume reduction } \\
\text { rate (\%) }\end{array}$ \\
\hline Pt. 1 & $2.0 \mathrm{~cm}^{3}$ & $1.5 \mathrm{~cm}^{3}$ & $0.026 \mathrm{~cm}^{3}$ & 98.7 \\
Pt. 2 & $3.6 \mathrm{~cm}^{3}$ & $2.88 \mathrm{~cm}^{3}$ & $0.4 \mathrm{~cm}^{3}$ & 88.89 \\
& Mean initial volume $=2.8 \mathrm{~cm}^{3}$ & & $\begin{array}{l}\text { Mean volume after 2nd sitting of } \\
\text { sclerotherapy }=0.213 \mathrm{~cm}^{3}\end{array}$ & Mean VRR $=92.39$ \\
\end{tabular}

Management of thyroid cysts using sclerosing agent was first reported by Edmonds et al. ${ }^{12}$ in 1987. Later Rozman et al., ${ }^{13}$ in 1989, introduced percutaneous ethanol ablation for cystic thyroid nodules. The proposed mechanism of sclerotherapy was epithelial cell dehydration and protein denaturation. This is followed by coagulative necrosis, reactive fibrosis, and small vessel thrombosis, which results in the obliteration of the cyst.

In a study, Verde et al. ${ }^{14}$ showed that volume reduction of nodule was greater and more significant in patients treated with ethanol injection than in simple aspiration.

In a study of 12 cases with cyst volume greater than $30 \mathrm{~mL}$ by Tarantino et al., ${ }^{15}$ all cases showed significant reduction in volume at the end of 6-9 months. In another study by Zingrillo et al., ${ }^{16}$ nodules with mean volume greater than $38 \mathrm{~mL}$ showed significant reduction in size after 2 years.

Jayesh in $2009^{17}$ performed a study in 15 patients. Ethanol was used as the sclerosing agent and was instilled under sonographic guidance. The amount of ethanol injected was about $50 \%$ of the amount of aspirated fluid. Follow-up USG was done every month for 3 months. Ethanol was reinjected when there was no significant reduction in the cyst volume. Following ethanol sclerotherapy, $4(26.6 \%)$ of 15 patients showed complete disappearance of the cyst, and $9(60 \%)$ showed significant reduction in the cyst volume (i.e., reduction of cyst volume by $\geq 50 \%$ of initial volume). Only two patients did not show significant reduction in cyst volume; both these patients had nodules with an initial volume of $\geq 20$ $\mathrm{cm}^{3}$. The overall success rate was stated to be $87 \%$. There were no complications attributable to ethanol injection during follow-up. In another study performed by Bennedbaek and Hegedüs ${ }^{18}$ on 66 patients with recurrent thyroid cystic nodule, using ethanol (instillation followed by emptying) and isotonic saline as sclerosing agents, an overall success rate of $82 \%$ was reported in the ethanol group, while the saline group showed only $48 \%$ reduction rate.

Higher success rate was recorded in our study (90\%) which could be due to difference in selection criteria of thyroid cysts and procedure.

Some authors have recommended aspiration of ethanol shortly (2-10 minute) after its administration. This procedure is more demanding, and usually two injections are required during a session. Kim et al. ${ }^{19}$ in 2005 studied and compared the therapeutic success rates in both techniques, and the results in the nonaspiration and aspiration groups were almost similar-96\% and $93 \%$, respectively, concluding that PEI without aspiration of ethanol-mixed fluid is the preferable method of treatment of benign cystic thyroid nodules from the perspective of both the physician and the patient. In a study by Cho et al. ${ }^{20}$ and Sung et al., ${ }^{21}$ the nonaspiration approach was used, as less volume of ethanol was needed, the procedure was shorter, and another injection was not needed to aspirate ethanol. The reported success rates ranged from $68 \%$ by Cho to $100 \%$ by Sung.
Comparable results are seen in the present study, where the success rates after 3 months of follow-up were recorded $90 \%$ after single session and $100 \%$ after second sitting of sclerotherapy using nonaspiration approach of ethanol sclerotherapy.

In 2013, Cetin et al. ${ }^{22}$ retrospectively evaluated medical files to present the results of 28 patients who were treated by Doppler USG-guided PEI into benign cystic thyroid nodule. Before percutaneous injection of ethanol, malignancies were excluded with fine-needle aspiration biopsy. $95 \%$ ethanol solution was injected to about half of the initial cystic volume, and the content of the cyst was aspirated after 10 minutes. At follow-up visits, nodule diameter, formation of fibrosclerosis, and nodule vascularization were evaluated. More than $50 \%$ reduction in nodule volume relative to the initial volume was defined as success. They reported $88.5 \%$ success rate with single application of PEl. Second installation in unsuccessful cases, increased the success rate to $92.9 \%$. Compared to them, our study shows better results (100\% success rate after second instillation), which could be explained by the fact that they used aspiration method of sclerotherapy, but in the present study non-aspiration method of sclerotherapy is used.

Ultrasound-guided PEl was performed in 33 patients by Halenka et al. ${ }^{23}$ with a success rate of $100 \%$ and significantly decreased cyst volume after 1, 3, and 6 months compared to the initial volume. Our study also shows $100 \%$ success rate (after reinstallation in nonresponders). It was noted in our study that cyst of $<2.5 \mathrm{~cm}^{3}$ showed mean reduction rate $>95 \%$, while cysts of $>4 \mathrm{~cm}^{3}$ had mean reduction rate of $71 \%$. Hence, it can be said that smaller cysts show better results than the larger ones.

The complications and adverse effects of PEI procedures are caused by ethanol leakage into the surrounding tissues. Most patients report mild temporary pain at the site of injection, radiating into the neck, chin, and ears, due to leakage of a little ethanol into the subcutaneous tissues. In different studies, pain was reported in $2.5 \%$ to $30 \%$ or, in large cysts, even $70 \%$ of patients reported pain. Occasionally, temporary vocal-fold paralysis and dysphonia or, rarely, transient thyrotoxicosis, have been reported.

Apart from transient burning pain at the site of injection, no other serious complications were noted in our study.

\section{Conclusion}

In the management of benign euthyroid cysts, USG-guided PEI is a cost-effective and efficient nonsurgical treatment modality with higher success rates. It is a relatively safe procedure with very low or no complication rates and has better patient compliance.

\section{Ethical Considerations}

Institutional ethics committee approval taken. 


\section{References}

1. Mazzaferri EL. Management of a solitary thyroid nodule. $\mathrm{N}$ Engl J Med 1993;328(8):553-559. DOI: 10.1056/NEJM199302253280807.

2. McHenry CR, Slusarczyk SJ, Khiyami A. Recommendations for management of cystic thyroid disease. Surgery 1999;126(6):1167-1171. DOI: $10.1067 / \mathrm{msy} .2099 .101423$.

3. Hammer M, Wortsman J, Folse R. Cancer in cystic lesions of the thyroid. Arch Surg 1982;117(8):1020-1023. DOI: 10.1001/ archsurg.1982.01380320016005.

4. Los Santos ET, Keyhani Rofagha S, Cunningham JJ, et al. Cystic thyroid nodules: the dilemma of malignant lesions. Arch Intern Med 1990;150(7):1422-1427. DOI: 10.1001/archinte.1990.00390190082012.

5. Cusick EL, Mcintosh CA, Krukowski ZH, et al. Cystic change and neoplasia in isolated thyroid swellings. Br J Surg 1988;75(10):982-983. DOI: 10.1002/bjs.1800751013.

6. Clark OH, Okerlund MD, Cavalieri RR, et al. Diagnosis and treatment of thyroid, parathyroid, and thyroglossal duct cysts. J Clin Endocrinol Metab 1979;48(6):983-988. DOI: 10.1210/jcem-48-6-983.

7. Jensen F, Rasmussen SN. The treatment of thyroid cysts by ultrasonically guided fine needle aspiration. Acta Chir Scand 1976;142(3):209-211.

8. Bennedbaek FN, Hegedüs L. Management of the solitary thyroid nodule: results of a North American survey. J Clin Endocrinol Metab 2000;85(7):2493-2498. DOI: 10.1210/jcem.85.7.6672.

9. Hegedüs L, Hansen JM, Karstrup S, et al. Tetracycline for sclerosis of thyroid cysts: a randomized study. Arch Intern Med 1988;148(5):11161118. DOI: $10.1001 /$ archinte.1988.00380050120018.

10. Lee SJ, Ahn M. Effectiveness of percutaneous ethanol injection therapy in benign nodular and cystic thyroid diseases: long-term follow-up experience. Endocr J 2005;52(4):455-462. DOI: 10.1507/ endocrj.52.455.

11. Livraghi T, Paracchi A, Ferrari C, et al. The treatment of autonomous thyroid nodules with percutaneous ethanol injection: 4 year experience. Radiology 1994;190(2):529-533. DOI: 10.1148/ radiology.190.2.8284411.

12. Edmonds CJ, Telle ZM. Thyroid cysts and their managements. Br Med J 1987;295(6597):529-533. DOI: 10.1136/bmj.295.6597.529.
13. Rozman B, Bence-Zigman Z, Tomic-Brzac H, et al. Sclerosation of thyroid cysts by ethanol. Periodicum Biologorum 1989;91:1116-1118.

14. Verde G, Paplni E, Pacella CM, et al. Ultrasound guided percutaneous ethanol injection in the treatment of cystic thyroid nodules. Clin Endocrinol 1994;41(6):719-724. DOI: 10.1111/j.1365-2265.1994. tb02785.x.

15. Tarantino L, Antonio G, Nicola M, et al. Percutaneous ethanol injection of large autonomous hyperfunctioning thyroid nodules. Radiology 2000;214(1):143-148. DOI: 10.1148/radiology.214.1.r00ja13143.

16. Zingrillo $M$, Torlontano $M$, Chiarella $R$, et al. Percutaneous ethanol injection may be a definitive treatment for symptomatic thyroid cystic nodules not treatable by surgery: Five-year follow-up study. Thyroid 1999;9(8):763-767. DOI: 10.1089/thy.1999.9.763.

17. Jayesh SR, Mehta P, Cherian MP, et al. Efficacy and safety of USGguided ethenol sclerotherapy in cystic thyroid nodules. Indian J Radiol Imaging 2009;19(3):199-202. DOI: 10.4103/0971-3026. 54879.

18. BennedbaekFN, Hegedüs L. Treatment of recurrent thyroid cysts with ethanol: a randomized double-blind controlled trial. J Clin Endocrinol Metab 2003;88(12):5773-5777. DOI: 10.1210/jc.2003-031000.

19. Kim DW, Rho MH, Kim HJ, et al. Aspiration of ethenol- mixed fluid percutaneous ethenol injection for benign cystic thyroid nodules: is advantageous? AJNR Am J Neuroradiol 2005;26(8):2122-2127.

20. Cho YS, Lee HK, Ahn IM, et al. Sonographically guided ethanol sclerotherapy on benign thyroid cysts: results in 22 patients. AJR Am Roentgenol 2000;174(1):2136. DOI: 10.2214/ajr.174.1.1740213.

21. Sung JY, Baek JH, Kim YS, et al. One step ethanol ablation of viscous cystic thyroid nodules. AJR Am Roentgenol 2008;191(6):1730-1733. DOI: 10.2214/AJR.08.1113.

22. Cetin B, Duman K, Karapinar U, et al. Engin Durusun percutaneous ethanol injection into thyroid cysts. J Med Updates 2013;3(3):142-145. DOI: $10.2399 / j m u .2013003007$.

23. Halenka M, Karasek D, Frysek Z, Ultrasound-guided percutaneous ethanol injection of small and medium-sized thyroid cysts with relatively small amount of ethanol.(Received: October 3, 2013; Accepted with revision: January 23, 2014; Available online: February 20, 2014. 